\title{
As fronteiras entre o romance e a autobiografia de Simone de Beauvoir: uma análise sob a perspectiva da liberdade ${ }^{1}$
}

Eduarda Pillar

Pontifícia Universidade Católica do Rio de Janeiro - PUC-Rio

Departamento de Comunicação Social - Bacharelado em Jornalismo

\section{RESUMO}

O objetivo deste artigo é analisar as fronteiras entre a escrita autobiográfica e a ficcional a partir da autobiografia A Força da Idade (1960) e do romance A Convidada (1943), ambos de autoria de Simone de Beauvoir. Para esta discussão, são analisadas as origens históricas das diferentes escritas de si, assim como os estudos de teoria literária identificados pelo período da "morte do autor". A partir desse panorama, observa-se as aproximações da escrita autobiográfica com a ideia de verdade; assim como a função da ficção que, desempenhada por meio do conceito de autoficção, pode se aproximar de uma noção mais completa do ser. Utiliza-se como recorte para o estudo das obras a noção de liberdade discorrida pela autora francesa nos dois livros.

\section{PALAVRAS-CHAVE}

Palavras-chave: Simone de Beauvoir; Ficção; Autobiografia; Autoficção; Liberdade.

\section{Introdução}

As diferentes faces da escrita de Simone de Beauvoir abrem espaço para diferentes estudos, que ganham força e relevância quando combinados com o caráter extremamente contemporâneo das ideias desenvolvidas. Depois de décadas, ainda há muita contundência ao que se refere aos pensamentos e ações existenciais da filósofa francesa. Trata-se de uma mulher questionadora dos valores burgueses, os quais permanecem no século XXI, e que reinventava-se constantemente, na busca por um movimento genuíno que pudesse se materializar por meio da escrita. O trabalho desempenhado pela autora não era somente teórico; também foram desenvolvidos diversos tipos de escrita que contribuíram, de diferentes formas, para o desenvolvimento do seu pensamento. A questão, por conseguinte, é observar a relevância das diferenças de linguagem e de estrutura para a percepção subjetiva de cada obra, pois a variedade de gêneros produzida não deve ser considerada uma mera mudança de técnica linguística. Sendo assim, o objetivo deste

${ }^{1}$ Derivado de monografia de graduação em Jornalismo, orientada pela professora Marcia Antabi e entregue em junho de 2020. 
artigo é analisar as divisas entre a escrita autobiográfica e a ficcional a partir de dois livros de autoria de Simone de Beauvoir. As obras analisadas são o romance $A$ Convidada (L'Invitée, 1943), o primeiro livro da escritora, e A Força da Idade (La Force de L'edad, 1960), uma das autobiografias publicadas por ela e que abrange o período da juventude como estudante e jovem autora.

A ideia de que Beauvoir escreve um romance autobiográfico - mencionado de forma contundente em muitas resenhas sobre o livro e na biografia Simone de Beauvoir: Simone de Beauvoir: écrire la liberté ${ }^{2}$ (Simone de Beauvoir: Escrita da Liberdade, tradução nossa, 2008) - não fecha o entendimento de suas obras e é somente um ponto de partida para melhor compreendê-las, tanto ao que se refere ao conteúdo, mas também aos gêneros literários que as duas são atribuídas. Tal aparente concordância não responde, por conseguinte, o questionamento no presente trabalho. É possível que a autobiografia de Simone tenha sido elaborada em ambos os livros? Para além disso, seria viável ainda que A Convidada, com o pressuposto de ficção que seu gênero carrega, seja uma porta aberta para o exercício pleno da liberdade tanto defendida e trabalhada pela autora? Essas são as perguntas que tentaremos elucidar, ainda que limitadamente e, por certo, conscientes da ausência de uma resposta definitiva.

É impossível retratar, em sua completude, a busca de Beauvoir por uma liberdade por meio de seus relatos memorialísticos. No entanto, trata-se de observar como a autora consegue aproximar-se do objeto final do processo existencial a partir de sua personagem no livro $A$ Convidada, ainda que diante da impossibilidade de encontrar uma verdade já superada em eras anteriores. A desvinculação com a verdade ou com o pacto autobiográfico ${ }^{3}$, desenvolvido pelo professor e ensaísta francês Philippe Lejeune, permite maior liberdade do autor para explorar novos aspectos de sua vida. Aquilo, portanto, que é passível de edição e pelo autor em uma escrita autobiográfica pode ser revelado pela escrita ficcional. Concordamos com a ideia da impossibilidade de completude de ambas as obras, visto que é possível identificar inclusive elementos de convergência que possam contribuir para o entendimento, não só de elementos biográficos da autora, mas aspectos mais subjetivos que contribuem para o entendimento do ser de Simone de Beauvoir.

\footnotetext{
${ }^{2}$ Biografia póstuma de autoria da filha adotiva de Beauvoir, Sylvie Le Bon de Beauvoir e Jacques Deguy, onde está escrito que o romance é livremente inspirado no trio Sartre-Olga-Castor, sendo este último nome um apelido carinhoso utilizado pelos amigos mais próximos de Beauvoir.

3 O pacto autobiográfico desenvolvido por Lejeune no livro O Pacto Autobiográfico: de Rousseau à internet (2014) consiste em um acordo implícito entre o autor e o leitor da obra, portanto ocorre independente da noção de verdade discutida por Klinger e no presente trabalho. Aquilo que é narrado e entregue ao público afirma seu gênero por meio de um "contrato que determina o modo de leitura do texto e engendra os efeitos que, atribuídos ao texto, nos parecem defini-lo como autobiografia" (p. 54).
} 


\section{Escrita autobiográfica e ficcional: as escritas de si e a morte do autor}

Segundo a doutora em literatura comparada pela UERJ (Universidade do Estado do Rio de Janeiro) Diana Irene Klinger, as escritas autobiográficas estão fortemente presentes na literatura contemporânea, por meio das autobiografias, reality shows, perfis, blogs e diversos outros exercícios do chamado ego-história que marcam a espetacularização do sujeito. Tais narrativas vivenciais proliferam-se no mercado editorial a fim de preencher uma demanda por modelos que encaminhem para o sucesso ou a completude existencial, mas que se afastam de um desenvolvimento individual efetivo. A autobiografia, nesse sentido, configura-se como um "substituto secular do confessionário eclesiástico e uma versão exibicionista do confessionário psicanalítico" (KLINGER, 2008, p. 13-14). Sendo assim, apresenta-se como uma herança do falar de si de épocas mais remotas que se combinam com processos contemporâneos e criam um cenário ainda amorfo e pouco definido. Compreender onde a escritora Simone de Beauvoir e suas autobiografias encontram-se dentro deste processo é um desafio que carece de uma resposta definitiva. Os escritos são anteriores ao advento da internet, importante veículo de disseminação e reformulação das biografias; no entanto, apresentam elementos que reafirmam a condição do autor no século $X X$, além de também revelarem os questionamentos que já estavam sendo estruturados na mesma época por críticos literários. Para que seja possível compreender quais são esses fatores e com qual ponto da literatura eles dialogam, é preciso voltar às origens das escritas autobiográficas e aos processos de transformação por qual esse tipo de texto passou ao longo da história.

Apesar desse fenômeno recente, cujo fim ainda não parece bem definido, a atividade de escrever sobre si não é atual, mas uma das tradições mais antigas do Ocidente. Assim como afirma Michel Foucault no ensaio A Escrita de Si (1992), já nos séculos I e II esse tipo de texto apresentava-se na forma de hupomnêmata e de correspondências na civilização greco-romana. Os dois gêneros são voltados para o autor a partir de um caráter transcendental em conjunto com um exercício de autoavaliação, embora exercidos de forma diferente em cada caso. Os hupomnêmatos eram cadernetas com anotações, citações, fragmentos, reflexões e pensamentos. Não constituem propriamente uma narrativa de si e são ausentes da necessidade de seguir determinada escola ou linha filosófica, mas uma forma de apropriação de leituras que estabelecem uma relação consigo mesmo. Esses pequenos textos escritos cotidianamente eram lidos e relidos pelo o próprio autor e vistos como uma forma eficaz de absorção de leituras e estudos, assim como de estabelecimento de uma coesão de pensamento e argumentos individuais. Dessa forma, 
os hypomnematas eram fundamentais para a construção do próprio ser, sendo esse livre de contradições e ambiguidades decorrentes de pensamentos fugazes. Sobre essa forma de construção de um sujeito bem delineado, Foucault explica ser como uma fuga do que era chamado, na época, de stultitia, palavra em latim utilizada para se referir aos devaneios da mente que afastam o leitor da verdade:

\begin{abstract}
A escrita, como maneira de recolher a leitura feita e de nos recolhermos sobre ela, é um exercício de razão que se opõe ao grave defeito da stultitia, que a leitura infindável se arrisca a favorecer. A stultitia é definida pela agitação do espírito, a instabilidade da atenção, a mudança das opiniões e das vontades, e, consequentemente, a fragilidade perante todos os acontecimentos que possam ter lugar; caracteriza-se também pelo facto de desviar o espírito para o futuro, de o tornar desejoso de novidades e de o impedir de se dotar de um ponto fixo pela posse de uma verdade adquirida. A escrita dos hypomnemata opõe-se a essa dispersão ao fixar os elementos adquiridos e ao constituir, de certo modo, um "passado" ao qual podemos sempre regressar e recolher-nos (FOUCAULT, 1992, p. 140).
\end{abstract}

As cartas, embora utilizadas a fim de se comunicar com um outro sujeito, não deixam de ser uma escrita de si igualmente significativa. Recorrentemente, durante 0 ato de produzir mensagens enviadas a amigos, conhecidos e familiares esmiuçava-se o cotidiano daquele que escreve; ou, de outra forma, dava-se conselhos e sermões ao remetente que muitas vezes convinham ao próprio autor. Dessa forma, encara-se consigo mesmo por meio de relatos de cotidianos, banalidades, atos corretos ou incorretos, reflexões diárias sobre qualquer tipo de assunto, destinadas, no entanto, a um outro. Diferentemente dos hupomnêmatos, que apresentavam um pressuposto mais acadêmico, as relações epistolares praticavam a liberdade de fluxo de pensamentos ancoradas na escrita despretensiosa. Eram, por conseguinte, muito utilizadas como uma atividade de resignação de si, ou seja, uma espécie de confessionário, no qual o valores e a moral cristã estão muito presentes. Por essa razão, assemelha-se aos escritos religiosos, que buscavam, por esse meio, investigar desvios da mente e da moral cristã, além de aprimorar-se espiritualmente.

A partir do Renascimento e da Reforma Protestante, esse tipo de escrita desprende-se de seu valor transcendental mais óbvio e passa a ser uma busca pela imortalidade do ser humano e construção de uma verdade. Por meio das escritas autobiográficas, acreditavase ser possível revelar o sujeito como ele é; esse caráter puro do ser, por conseguinte, será transmitido pelos séculos à frente. Tal prerrogativa torna indispensável à noção daquele que escreve; o autor, dessa forma, é peça chave para qualquer tipo de escrita 
autobiográfica, mas também para todo o escopo de obras literárias, como é apontado por Foucault e também pelo filósofo e escritor francês Roland Barthes. A ideia de que há uma essência daquele que escreve em todo texto é um resquício de uma noção religiosa do ser. Ora, a ideia de um desvelamento do autor por meio de sua obra possibilita seu entendimento completo como sujeito, o seu lado mais puro e verdadeiro. Barthes chama atenção no ensaio A Morte do Autor (1967) ao fato de que essa noção contribui, não só para a mitificação daquele que escreve, mas também para o excesso de autoridade daquele que investiga: o crítico literário moderno é o responsável por investigar e lapidar o gênio que será incontestavelmente venerado pelo leitor.

Esse cenário da literatura moderna, no entanto, não se construiu à parte das mudanças sociais e políticas, as quais Foucault contundentemente ressalta. A corrente positivista do início do século XIX foi muito significativa na reafirmação do pensamento devido à importância dessa ideologia à supervalorização do estudo e da categorização científica de todas as áreas do conhecimento, inclusive da literatura e, consequentemente, da ideia de autoria. Sendo assim, um escritor moderno, por trás da sua escrita, desenvolve, a partir dela, significados anteriores, premeditados, que por meio de um conjunto de obras, constrói-se um sentido maior e concreto muito vinculado ao que é chamado de autoria; ou um sentido que justifique todo o escopo de escritos. Procuram-se indícios externos sobre a vida pessoal e as referências literárias que possam delinear um sentido para o texto. Sobre isso, Barthes exemplifica por meio de gêneros e artistas que fazem parte desse processo:

\begin{abstract}
O autor ainda reina nos manuais de história literária, nas biografias de escritores, nas entrevistas dos periódicos e na própria consciência dos literatos, ciosos por juntar, graças ao seu diário íntimo, a pessoa e a obra; a imagem da literatura que se pode encontrar na cultura corrente está tiranicamente centralizada no autor, sua pessoa, sua história, seus gostos, suas paixões; a crítica consiste ainda, o mais das vezes, em dizer que a obra de Baudelaire é o fracasso do homem Baudelaire, a de Van Gogh é a loucura, a de Tchaikovski é o seu vício: a explicação da obra é sempre buscada do lado de quem a produziu, como se, através da alegoria mais ou menos transparente da ficção, fosse sempre afinal a voz de uma só e mesma pessoa, o autor, a revelar a sua "confidência" (BARTHES, 2004, p. 58).
\end{abstract}

Sob essa perspectiva, exaure-se o texto a uma interpretação, a qual a participação do leitor não é levada em conta. Esta ideia de autor é concedida, segundo Foucault em $O$ que é um autor? (1970), como uma construção burguesa marcada pelo individualismo, responsável por ser uma reguladora da ficção. Pouco, desta forma, sobra de atividade para 
o leitor: os autores relevantes já foram escolhidos por ele, assim como as obras e seus significantes correspondentes. Diferentemente de escritos da Idade Média, dos quais a simples presença no papel já atesta seu valor de autoridade; antes do leitor moderno ler qualquer texto, será indagado de onde veio, quem o escreveu, quando, em qual circunstância ou a partir de que projeto, para que assim possa atestá-lo como obra literária. Tal medida, muitas vezes necessária, tendo em vista o crescente número de escritos e alfabetizados - números incomparáveis aos do século XV -, também é castradora, pois limita a apreciação literária e o movimento mutualista entre aquele que escreve e aquele que lê.

Em Por uma Moral da Ambiguidade (Pour Une Morale de L'ambiguïté, 1947), Simone de Beauvoir discorreu brevemente sobre a ideia de fracasso e êxito que se atribui a diversos aspectos da vida do homem e em suas obras. No caso da arte, por exemplo, ela transita entre esses dois valores ao longo da história, podendo acatar a adesão das consciências humanas ou não. Um caso bastante conhecido é o pintor Van Gogh, que, na época em que produzia os quadros não atingiria o enorme sucesso que, mais tarde, atribuiria seu nome à genialidade. Antes disso, seria possível considerá-lo um fracasso? O que mudara, se os quadros continuam essencialmente os mesmos ao longo dos anos? Sobre esse aspecto, Beauvoir explica que "é exatamente isso que torna a crítica tão fácil, a arte tão difícil" ( $p$. 105). A pintura, assim como a literatura, nunca é inteiramente dada, pode ser sempre desvelada para além das intenções dos próprios artistas, por essa razão será sempre uma figura inacabada; no entanto, o crítico, de forma geral, tem como função constituir os limites, aqueles construídos pelo próprio autor, mas que sempre são capazes de ultrapassá-lo.

A ideia de uma possível finitude foi superada ainda no mesmo século, momento marcado pela profissionalização do escritor e pelo período, chamado por Barthes de "morte do autor" (1967, p. 57), utilizado também por Foucault, mas com resguardos. O autor, a partir desse momento, é contestado pelos críticos literários e perde o caráter de semideus a ele atribuído; declara-se seu fim e, ao mesmo tempo, deixa um vácuo. Para Foucault, esse vazio é substituído pela função autor (Ibid, p. 47), aquele que, por meio de diferentes vozes e discursos, constrói obras cujas particularidades, estruturas linguísticas, funções e ideias têm como o autor somente uma das variáveis; não mais a origem de todas as explicações e traduções possíveis. 
Em contrapartida, o movimento moderno da literatura transforma o autor em um ser opaco à linguagem, ou seja, as palavras passam a estar acima de suas individualidades. O significado, desta forma, é construído a partir do leitor, não mais de quem escreve. A pessoa que lê pode, a partir de sua própria individualidade e subjetividade, desenvolver um sentido próprio para a escrita que permite tal abertura. O romancista Silviano Santiago chama essa possibilidade interpretativa de uma história mal contada, em Meditação sobre o ofício de criar (2008). Toda a boa literatura, segundo o autor, apresenta uma parte bem escrita, ou seja, bem delineada em seus sentidos; e outra pouco explicada, mal escrita. Esta, no entanto, é a que importa, já que permite um trabalho ativo do leitor com as possibilidades interpretativas. Sobre isso, Foucault adverte que não se deve compreender a inexistência do autor como a oportunidade de constituir a escrita como uma terra de ninguém, ausente de princípios teóricos e organizacionais; dentro das inúmeras interpretações, cabe aos estudiosos concederem a validez de cada uma.

O século $X X$, portanto, é marcado pela morte do autor, mas também pelo seu retorno acompanhado da reafirmação da subjetividade literária; aquilo que está nas "entre linhas", ou seja, o que pode ser o "rumor da língua" (BARTHES, 1988, p. 93). A ideia de autor, no entanto, difere-se da ideia presente no século XVI; ela volta a partir de uma nova concepção relacionada à presença do autor por meio de um empreendimento filosófico: a constituição e a exploração de novas ideias. Os estudos desenvolvidos por Foucault após 1970 já não se baseiam mais na concepção de um defunto autor. Em argumentos propostos à Sociedade Francesa de Filosofia, o teórico pede ironicamente para que os presentes retenham suas lágrimas, pois o autor, de fato, nunca esteve realmente morto.

Apesar de Simone de Beauvoir ser um indivíduo que, como mulher no século $X X$, diferenciava-se por uma postura acadêmica; pela seriedade no empreendimento à escrita; e principalmente, pela liberdade com a qual exercia seus pensamentos e ações que, muito constantemente, chocava-se com uma série de noções pré-estabelecidas, a escritora francesa ainda era uma mulher que estava dentro de um contexto histórico e social definido. Momento esse, descrito pela historiadora Eliana Calado, em sua tese Autobiografias de Simone de Beauvoir: Sujeito, Identidade, Alteridade (2012), em que a sociedade burguesa era centrada no sujeito. Sendo assim, Beauvoir não diferencia-se dos críticos literários do século XX que trabalhavam para a construção da noção de autor e de autoria. Essa semelhança fica mais clara quando afirma que "um livro só adquire seu sentido verdadeiro quando se sabe em que situação, em que perspectiva foi escrito e por quem" (BEAUVOIR, 1960, p. 11). Tanto o pressuposto da existência de um sentido 
verdadeiro para uma obra, quanto o de que o autor é o único capaz de encaminhar a essa interpretação estão presentes nessa afirmação. Elementos da teoria literária amplamente difundidos e, posteriormente, como foi explanado, contestados por Barthes, reafirmam a existência de Beauvoir em uma determinada época. Ademais, a busca por alguma unidade que justificasse sua identidade, além de seu nome próprio mencionada por Calado está estritamente relacionada à diferenciação feita por Foucault entre o nome do sujeito e o do autor. Esta último refere-se à autoria e abrange um leque de obras que interagem entre si, dessa forma contribuem na construção da noção do artista e do gênio. De fato, a historiadora identifica em Beauvoir a organização empregada na preservação de correspondências, anotações e diários que, mais tarde, foram matéria-prima para a confecção de suas memórias, além das biografias e publicações póstumas da autora. Em suma, o indivíduo estava em alta no cenário burguês no qual os filósofos viviam, o que leva Calado à seguinte conclusão sobre as intenções da autora ao escrever sobre si:

[...] ao longo de suas autobiografias, Beauvoir buscava determinado fio condutor, alguma unidade que justificasse sua identidade, além de seu nome próprio. Não importa se esta atitude é questionável ou não, se ela é "executável"; o que interessa é a análise desta procura por uma suposta unidade, da qual não foge Beauvoir, e que é comum a vários autores de narrativas autorreferenciais, assim como a autores de biografias (CALADO, 2012, p. 19- 20).

\section{Autoficção e a Aproximação com as Verdades}

Quando desprendemo-nos das amarras do essencialismo, abrimos uma gama de possibilidades difíceis de serem organizadas. Eliana Calado atenta ao fato de que a ausência de uma verdade absoluta não pressupõe um niilismo, mas um escopo de possibilidades definidas sempre passíveis de novas incorporações. Este novo campo pouco explorado da crítica literária desestabiliza, porém, todo uma estrutura de gêneros linguísticos bem definidos. Se não há necessariamente um vínculo com a verdade, o que faz uma autobiografia ter esse nome? Qual é, então, a real diferença entre a ficção e as biografias, se nenhum desses dois tipos de textos são capazes de estabelecer uma verdade total sobre aquele que escreve? Para responder essas perguntas é preciso mencionar que o pressuposto da ausência de algo absoluto não anula a busca feita, tanto pelos autores, quando os leitores. Ao conscientizar-se sobre a impossibilidade de uma completa sinceridade por parte de Beauvoir quando escreveu sua autobiografia, a potência da escrita desenvolvida por ela não é enfraquecida, mas o contrário: amplifica-se, busca-se nas entrelinhas e, como Santiago menciona, na história mal contada. 
Sendo assim, os livros A Convidada (1943) e A Força da Idade (1960), de Beauvoir, apresentam-se ambos como escritos incompletos; aproximam-se em possibilidades interpretativas, e se relacionam em caráter mutualista para a aproximação da verdade, essa inconcebível nos âmbitos atuais, mas sempre almejada. São, como Diana Klinger especifica, diferentes faces de um assunto, fenômeno ou acontecimento; levando em conta essas perspectivas garante-se um estudo mais aprofundado sobre qualquer questão, trata-se de uma aproximação com a verdade, uma busca ininterrupta que se assemelha a um trabalho de Sísifo.

A teoria de Klinger busca, no entanto, reestruturar classificações hoje ultrapassadas, não somente pelo fenômeno da morte do autor, mas também pelo novo cenário da literatura que reinstaura o artista em um campo bastante privilegiado das ego-histórias. Tal trabalho está centrado no esforço de ressignificar e ampliar o conceito da autoficção ${ }^{4}$, fazendo assim com que uma nova visão do sujeito dentro da literatura possa ser criado para além da noção individualista burguesa. Em suma, o trabalho da pesquisadora busca colocar a autoficção "no coração do paradoxo deste final de século XX: entre o desejo narcisista de falar de si e o reconhecimento da impossibilidade de exprimir uma 'verdade na escrita'" (KLINGER, p. 22).

O autor, portanto, inicia uma nova trajetória na literatura, na qual a narrativa biográfica excede suas fronteiras para o ficcional e o pressuposto da verdade não é mais uma questão a priori para o exercício dessa escrita. Sendo assim, a ideia de que a memória possa trair pequenos relatos de uma obra, adendo feito por Simone de Beauvoir em A Força da Idade (1960), não se configura como um problema dentro do cenário atual, ainda que o comentário tenha sido feito em um contexto no qual esta discussão ainda não era abordada. Esse campo indefinido, no qual o sujeito que escreve imerge, ultrapassa, dessa forma, a veracidade para adentrar na ideia de mito discutida por Klinger.

Segundo a pesquisadora, a autofiç̧ão está intrinsecamente relacionada à construção do mito do autor, pois representa a linha transitória entre a confissão e a mentira. Trata-se de uma visão romanceada de si mesmo que se associa aos estudos psicanalíticos do século

\footnotetext{
${ }^{4}$ O conceito de autofiç̧ão, inventado em 1971 pelo crítico e teórico francês Serge Doubrovsky, carece de uma ideia bem definida. Surgiu pela primeira vez na obra Fils (1977), criada com o intuito de preencher uma lacuna apontada por Lejeune em O Pacto Autobiográfico (Le Pacte Autobiographique, 1975) que indica a inexistência de um romance cujo nome do personagem coincidisse com o do autor. Nesse livro, Doubrovsky escreve na contracapa: "Autobiografia? Não. Esse é um privilégio reservado aos grandes desse mundo, no crepúsculo da vida, e num belo estilo. Ficção, de eventos e de fatos estritamente reais, por assim dizer, autoficção, por se haver confiado a linguagem de uma aventura à aventura da linguagem, fora dos limites da sensatez/sabedoria [sagesse] e da sintaxe do romance, tradicional ou novo".
} 
XX. Ora, dentro de um consultório de psicanálise é bem compreendido que há o discurso daquele que é analisado e as possíveis interpretações e associações do analista a partir do que é dito. "Quer dizer que o sentido de uma vida não se descobre e depois se narra, mas se constrói na própria narração: o sujeito da psicanálise cria uma ficção de si", explica Klinger (2006, p. 54). Ela exemplifica com o último romance de Silviano Santiago, O Falso Mentiroso: Memórias (2004), cuja contracapa explica o título: "paradoxo atribuído a Euclides de Mileto, cuja forma mais simples é: se alguém afirma 'eu minto', e o que diz é verdade, a afirmação é falsa; e se o que diz é falso, a afirmação é verdadeira e, por isso, novamente falsa etc". Deixa assim dúbia a veracidade do livro ao mesmo tempo que questiona a própria ideia de verdade que o gênero autobiográfico induz. Assim como Barthes quando escreve no livro de memórias Roland Barthes por Roland Barthes (1975), "tudo o que aqui se diz deve ser considerado como dito por um personagem de romance"; deixa claro, dessa forma, a insuficiência da biografia tradicional como constituidora da verdade e a própria extensão da ficção ou da mentira como tipos de escritas que se aproximam de algo que possa ser verdadeiro.

É por meio destes parâmetros que Klinger aproxima o texto autobiográfico do conceito de

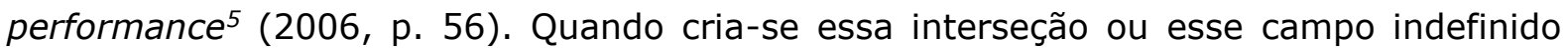
entre a ficção e a escrita autobiográfica, os conceitos de autor e personagem também se fundem, pois o sujeito que escreve acaba, conscientemente ou não, criando um personagem sobre si mesmo. Isso pode ser relacionado à própria ideia mitificada do autor ou do gênio, aquela figura que é admirada quase tanto quanto a sua obra. Não se pode dizer que essa seja a representação real do sujeito, mas um papel o qual interpreta fazendo daquilo um personagem próprio. Sendo assim, o texto autobiográfico configurase como a dramatização de si e, como em um palco de teatro, o autor está sempre entre a representação de si e a de um outro. Essa ambivalência que está presente, tanto no texto, quanto na dramatização é o que aproxima as escritas de si do teatro convencional. No entanto, a arte performática, diferentemente deste último, está ainda mais interligado às autobiografias, pois pressupõe uma exposição maior do sujeito que pratica, além de ter um caráter inacabado, de constante construção subjetiva, que se assemelha a próprio trabalho da escrita de si. Assim, para Klinger, "a obra de autoficção também é comparável à arte da performance na medida em que ambos se apresentam como textos inacabados,

\footnotetext{
${ }^{5} \mathrm{O}$ conceito de performance desenvolvido por Klinger trata, tanto do termo em inglês que significa atuação, desempenho, rendimento, quanto da sua reformulação nos anos 1950 dentro do campo da arte como uma atividade performática, uma dramatização contida de um sentido específico para determinada cultura. Sendo assim, Klinger explica que "o autor é considerado enquanto sujeito de uma performance, de uma atuação, que 'representa um papel' na própria 'vida real', na sua exposição pública, em suas múltiplas falas de si, nas entrevistas, nas crônicas e autorretratos, nas palestras" (p. 57).
} 
improvisados, work in progress, como se o leitor assistisse 'ao vivo' ao processo da escrita" (p. 59).

Beauvoir dá um exemplo claro desse processo dramatúrgico ao escrever em seu livro de memórias sobre um ator chamado Dullin que conhecera em Paris. Quando observava a montagem de uma peça em que ele atuava e ao mesmo tempo dirigia, observava momentos de extremo estresse e euforia, quando o artista exalava, como por um acesso, suas angústias ao mesmo tempo que interpretava o papel: "Em meio a uma réplica de Shakespeare, sem mudar de tom, encadeava uma imprecação desesperada ou furiosa: 'Mas isso é o fim. Não sou auxiliado. É inútil continuar'"; depois de se expressar comovidamente, "bruscamente voltava a ser Ricardo III" (BEAUVOIR, 1960, p. 127). Tal passagem, de forma mais figurativa e objetiva, portanto mais caricatural do que Klinger busca comunicar por meio da ideia de performance, evidencia a impossibilidade da completa transmutação do ator no personagem que interpreta, sem que vestígios significativos desse sujeito também se expressem.

Partindo da tese desenvolvida pela teórica da literatura, é possível constituir um paralelo para além desse relato, envolvendo as duas obras da autora francesa. Não somente estende-se a autobiografia para a ideia de um processo de construção ilusória de um sujeito Beauvoir, mas também é admissível que a autora possa se apresentar de forma ainda mais profunda por meio das personagens criadas em sua primeira obra ficcional. Beauvoir pode ter sido, dentro do conceito performático de Klinger, atriz de si quando escreveu $A$ Força da Idade, mas também pode ter se escondido por trás da personagem Françoise de $A$ Convidada para que, dentro de uma peça tradicional, com espaços e tempos fictícios, pudesse adentrar mais profundamente dentro de si.

Por meio da leitura de A Convidada (1943) observamos imediatamente que o contexto histórico, tanto da escrita, quanto do desenrolar da narrativa construída se assemelham. Beauvoir escreve A Convidada durante o desencadear da Segunda Guerra Mundial, o mesmo período histórico da própria narrativa. A descrença em relação à possibilidade de uma guerra sob o território francês é unânime entres os artistas de ambas as realidades. Sobre isso, Beauvoir escreve que a personagem Françoise "nunca acreditara na possibilidade de uma guerra; um conflito armado é como uma tuberculose, ou os desastres de uma estrada de ferro; isso não vai acontecer comigo. Essas coisas só acontecem aos outros" (p. 14). Sendo assim, era preciso que não se pensasse nessa terrível possibilidade, visto que "se estourasse um dia, nada mais teria importância, nem mesmo viver ou 
morrer". A esse respeito, a autora escreve em A Força da Idade: "no outono de 1929 compartilhamos a euforia da esquerda francesa. A paz parecia definitivamente assegurada. A expansão do Partido Nazista na Alemanha representava apenas um epifenômeno sem gravidade" (p. 21).

Tanto Beauvoir quanto Sartre, embora simpatizassem abertamente com o socialismo, estavam longe de serem militantes; pelo contrário consideravam, como foi relatado em $A$ Força da Idade (1960), palavrear, declamar, manifestar, pregar uma agitação vã, a qual, feitas pelos intelectuais de esquerda, só the faziam dar de ombros (p. 265). Esses sentimentos eram acompanhados de uma constante descrença de que a guerra deflagrasse em território francês, um excesso de positividade abruptamente interrompido pelas tropas nazistas e que, segundo Calado, era compartilhada por grande parte da classe artística. Os desdobramentos da crise econômica dos Estados Unidos em 1929, assim como a Guerra Civil Espanhola (1936-1939) e a ascensão do nazismo (1933-1945) são planos de fundo de parte dos escritos discorridos nesta segunda obra autobiográfica; e, de fato, estabelecem-se com poucos detalhes - ou quase indiferença - dentre as atividades amplamente descritas das viagens feitas no interior do país e regiões da Europa ${ }^{6}$.Isso provavelmente se deve ao fato de que as memórias escritas, muitas vezes baseadas em diários conservados pela autora e também na própria memória, provavelmente não foram suficientes para resgatar reflexões a respeito das questões políticas que, no entanto, não devem ter sido feitas, visto a falta de interesse da autora sobre esses assuntos na época. Uma Beauvoir mais madura e atenta aos acontecimentos do mundo escreve, depois, na autobiografia: "sinto-me hoje estupefata ao lembrar que tenhamos podido registrar esses acontecimentos com relativa serenidade". Apesar da indignação da esquerda francesa, ela afirma que o grupo "recusava-se a encarar de frente as ameaças que esse nazismo fazia pesar sobre o mundo" (p. 150).

Tal segurança é analisada por Beauvoir trinta anos depois ${ }^{7}$, quando escreve a segunda autobiografia, como um equívoco que era muito bem recebido pela mente deles, visto que produziam um conforto em relação às angústias do futuro. Sendo assim, ela afirma: "não percebíamos em nós nada de opaco ou turvo; pensávamos ser pura consciência e pura vontade. [...] Como nossa ignorância dissimulava a maior parte dos problemas que nos deveriam ter inquietado, contentávamo-nos intrépidos" (1960, p. 22). A escritora deixa

\footnotetext{
${ }^{6}$ Quando conheciam a Espanha em plena Guerra Civil, por exemplo, ouviam os rumores do que acontecia "bebendo manzanilla, roendo azeitonas pretas e descascando enormes camarões" (BEAUVOIR, 1960, p. 91).

7 O espaço de tempo entre a realização e a análise posterior de Beauvoir tem um sentido que explica em $A$ Força da Idade: "pode-se, com alguma distância, descobrir de maneira desinteressada fatos, sentimentos, cuja revelação imediata teria constituído uma manobra ou, pelo menos, uma intervenção" (p. 31).
} 
claro, por conseguinte, que a falta de reflexão sobre diversos pontos que envolviam a vida dos dois conduzia-os ao exercício da má-fé 8 . O que achavam na juventude ser a liberdade, era nada mais do que o uso de privilégios pelos quais não tinham consciência de possuírem. O próprio conceito de liberdade era, até então, utilizado na época de forma leviana, como um ideal vago, visto que não haviam se debruçado sobre isso e a filosofia existencialista ainda não tinha tomado forma.

\begin{abstract}
Nossa indiferença ao dinheiro era um luxo que podíamos nos oferecer, porque tínhamos o suficiente para não passar necessidades e não ser acuados a trabalhos penosos. Nossa grandeza de espírito, nós a devíamos a uma cultura e a projetos acessíveis tão somente à nossa classe. Era nossa condição de jovens intelectuais pequeno-burgueses que incitava a nos acreditar incondicionados (BEAUVOIR, 2010, p. 27).
\end{abstract}

Essa condição própria da burguesia do século XX é o que Beauvoir também retrata no romance A Convidada (1943), antes de realizar a autocrítica mencionada. A personagem Françoise encontra-se dentro de um mundo bem estruturado e aparentemente sem falhas. Ela exerce a profissão de escritora livremente; possui uma relação com Pierre sem as amarras relacionadas à monogamia e ao matrimônio; e vive à parte dos valores sociais e materiais instituídos pela sociedade burguesa da época. O aparente controle sobre a própria vida é reforçado pelo seu papel dentro daquele cenário artístico e intelectual: a personagem é dramaturga e escreve a peça a qual é desenvolvida e apresentada ao longo da trama. Assim como Beauvoir, Françoise tem o controle sobre a narrativa que escreve e; no entanto, no desenrolar da própria história a protagonista perde o controle e a estabilidade, antes uma certeza, torna-se mais fragmentada. A partir disso, é possível perceber $o$ desenvolvimento de uma metalinguagem que se apresenta pelo questionamento da possibilidade de uma total regulação daquele que escreve sobre aquilo que é escrito. Mais uma vez fica evidente a tese de Klinger, na qual acredita-se na impossibilidade do autor de construir um personagem sem colocar, sob algum aspecto, elementos pessoais; mesmo que esse esteja conscientemente tentando afastar-se de si mesmo, tal prerrogativa foge de seu controle.

Percebe-se que as angústias de Françoise eram, pelo menos durante um período de sua vida, também as da autora; a trapaça que, mais tarde, será teorizada como má-fé dentro da filosofia existencialista foi exercida por Beauvoir. Antes mesmo que tivesse revelado anos depois na autobiografia, com o espaço de tempo que diz ser necessário para a

\footnotetext{
${ }^{8}$ Conceito criado por Beauvoir que consiste em um desejo de identificação com os valores e estruturas dadas pela sociedade, ação que impede reação de liberdade. Ainda que o ser tenha se deparado com a possibilidade de existência, não trabalha no desvelamento do mundo, mas se compraz a alguma configuração existente. 0 empreendimento, portanto, é suscetível aos deslizes causados pela própria mente.
} 
avaliação mais racional das experiências, já havia discorrido sobre essa questão quase vinte anos antes por meio do romance.

\section{Considerações Finais}

As questões abordadas neste trabalho carecem de uma resposta definitiva; tratou-se, de fato, de compreender a impossibilidade de chegar na tão almejada verdade biográfica. Sendo assim, observamos por meio dos estudos de Foucault as origens dessa atividade da escrita as quais buscam um sentido para si. Seja por meio da hypomnemata, das cartas, dos diários ou das autobiografias, o sujeito está sempre em busca dele mesmo. Consegue encontrar aquele autor bem acabado, definido e mitificado pelos teóricos literários? Provavelmente não; por isso a incapacidade de chegar ao fim torna-se tão evidente. Igualmente é impossível que consiga definir a própria obra, pois essa ultrapassa o autor tão logo ele a cria. Atendo-se nisso, fica evidente o caráter ilimitado dos livros estudados de Simone de Beauvoir. A derradeira morte do autor propagada por Barthes, longe de ser um projeto de luto, é uma porta aberta para o leitor e o pesquisador conseguirem realizar suas contribuições dentro daquelas histórias mal contadas, as brechas que inevitavelmente existirão dentro de qualquer história.

Por essa razão, a teórica Diana Klinger afirmou a importância da busca pela verdade mesmo que essa seja inalcançável. O processo é imprescindível para a compreensão mais minuciosa do autor, da obra e das questões sociais e históricas que envolvem o objeto de estudo. A procura pela aclamada verdade deve ser feita, no entanto, por meio de outro contexto. Faz-se isso ao mesmo tempo em que se questiona a relação direta da autobiografia com a veracidade; incorpora-se a ficção como um produto, ainda que romanceado, fundamental para a nova metodologia. A justificativa para agregar esse novo gênero literário é a ideia de que o campo ficcional é propício para desempenhar certas liberdades impossíveis de serem desempenhadas por meio de uma escrita autobiográfica.

Dentro dessa perspectiva, as obras de Simone de Beauvoir A Força da Idade (1960) e A Convidada (1943), embora categorizadas por diferentes gêneros - uma autobiografia e o outro um romance, respectivamente - apresentam uma característica fundamental em comum: revelam aspectos sobre o sujeito que escreve e se aproximam, por meio de um trabalho mutualístico, do que poderia constituir a verdade do ser Beauvoir. No entanto, como foi alertado no início da monografia, não buscamos aqui revelar a autora, realizar 
uma nova biografia, mas estudar as reais relações da escritora francesa com o conceito muito pregado e estudado por ela: o de liberdade. Por meio do estudo de trechos dos dois livros foi possível compreender com maior amplitude as questões que envolvem o próprio grupo social a que Beauvoir pertencia na época; a partir disso, observou-se os momentos que se desempenha uma má-fé por parte da autora, assim como aqueles em que age de acordo com o seu desenvolvimento pessoal libertário.

Sendo a autora francesa parte do cotidiano de um período histórico e social, é esperado que ela esteja de acordo com as intenções autobiográficas que eram desempenhadas em meados do século XX. Como a historiadora Eliana Calado evidencia, ainda que Beauvoir tenha sido uma mulher que confrontava os valores e a moral burguesa da época, era um sujeito que vivia em um contexto; tanto as reivindicações quanto as adaptações estarão sempre relacionados àquele cenário. Esse ponto de vista permitiu-nos perceber um ímpeto de busca pela verdade em A Força da Idade, aquela que mais tarde na história seria questionada por Barthes. Diversos trechos destacados neste trabalho apontam para a tendência de construir um autor, iluminar as possíveis brechas as quais poderiam induzir a interpretações que seriam consideradas equivocadas sobre ela e as obras que desenvolveu. Essa tentativa de controle sobre si e sobre a própria história mostra-se sempre incapaz de chegar a um fim; isso a impele a escrever mais sobre determinados anos e momentos da vida que ainda não haviam sido esclarecidos. Por fim, Beauvoir deixa quatro autobiografias, mas não consegue completar a tarefa. O que o ocorre é, contraditoriamente, o oposto: na busca pelo próprio desvelamento, revela-se toda a complexidade de um sujeito, uma classe e um pensamento filosófico.

\section{Referências Bibliográficas}

BARTHES, Roland. O rumor da língua. Tradução Leyla Perrone Moisés. São Paulo/Campinas: Brasiliense. Ed. da Unicamp, 1988 [1984].

BEAUVOIR, Simone. A Cerimônia do Adeus. $3^{a}$ edição. Tradução: Sérgio Millet. Rio de Janeiro: Nova Fronteira, 1982.

1976.

. A Convidada. $2^{a}$ edição. Tradução: Vítor Ramos. São Paulo: Circulo do Livro S.A.,

. A Força da Idade. 2a edição. Tradução: Sérgio Millet. Rio de Janeiro: Nova Fronteira, 2010.

. Memórias de Uma moça bem-comportada. $2^{a}$ edição. Tradução: Sérgio Millet. Rio de Janeiro: Nova Fronteira, 2009.

. Por uma Moral da Ambiguidade. $1^{a}$ edição. Tradução: Marcelo Jacques de Moraes. Rio de Janeiro: Nova Fronteira, 2005.

CALADO, Eliana. Autobiografias de Simone de Beauvoir: Sujeito, Identidade, Alteridade. 2012. Tese para obtenção do título de Doutor em História: História Cultural - Programa de Pós-Graduação em História da Universidade de Brasília, Brasília, 2012. 
CARVALHO, M. P.; VIANA, M. R. Existencialismo e expressão literária: Simone de Beauvoir. 2008. 17f. Artigo acadêmico publicado na Revista Perspectiva Filosófica - Universidade Federal de Pernambuco, Pernambuco, 2008.

CARVALHO, M.; FIGUEIREDO, V. A questão da morte do autor em Foucault. São Paulo: ANPOF, 2013, p. 183-190. Anais do XV Encontro Nacional da ANPOF, 2012, Curitiba.

FOUCAULT, Michel. A escrita de si. Ditos e escritos. Vol. V. Ética, sexualidade e política. Tradução de Elisa Monteiro e Inês Autran Dourado Barbaso. Rio de Janeiro, Forense, 2004. KLINGER, Diana. Escritas de si, escritas do outro: autoficção e etnografia na narrativa latino-americana contemporânea. 2006. 209 f. Tese para obtenção do título de Doutor em Letras: Literatura Comparada - Instituto de Letras da Universidade Federal do Rio de Janeiro, Rio de Janeiro, 2006.

LEJEUNE, Philippe. O Pacto Autobiográfico: De Rousseau À Internet. $1^{a}$ edição. Minas Gerais: UFMG, 2008.

SILVIANO, Santiago. Meditação sobre o ofício de criar. 2008. Texto de palestra realizada no Sesc, Copacabana. Rio de Janeiro, 2008.

VIANA, Márcia Regina. Liberdade e existência: os movimentos do existir em Simone de Beauvoir. 2010. 18f . Artigo acadêmico publicado na Revista Estudos Filosófico no 5 /2010. UFSJ - São João del-Rei-MG. 